\title{
Therapy-Related Myelodysplastic/Myeloproliferative Neoplasm
}

National Cancer Institute

\section{Source}

National Cancer Institute. Therapy-Related Myelodysplastic/Myeloproliferative

Neoplasm. NCI Thesaurus. Code C82397.

A myelodysplastic/myeloproliferative neoplasm arising as a result of the mutagenic effect of chemotherapy agents and/or radiation that are used for the treatment of neoplastic or non-neoplastic disorders. 